\title{
Modality in Tae' language: a grammatical-lexical view
}

\author{
Kisman Salija - Jusmianti Garing - Idawati Garim
}

\section{DOI: 10.18355/XL.2017.10.04.18}

\begin{abstract}
There are many ways to find modality in languages. Modality of language can be expressed through grammatical or lexical feature. However, modality in Tae' language specifically can be described through both these features. This research aims to express the modality in Tae' language based on grammatical-lexical point of view. This is a descriptive qualitative research using library research methods. Library research aims to get of completed and detail data. Further, this research analyzes eighteen discourses of Tae' language consisting of folklore, fable, messages, and Tae' specific food. The result shows that there are some features marking modality in Tae' language that expressed through grammatical and lexical feature. Grammatical modality of Tae' established through affixation process, i.e. prefix la-, and suffixes ri, -ra functioning as verbs and particles. Further, modality in Tae' is also established by lexical feature using the words melo, parallu, musti, bela, wa'ding, bang, omi, sia, kade, le', dau, tae, tannia, saba, iake, and kumua functioning as auxiliary verbs, particles, negations, and conjunctions. Semantically, these forms mark epistemic and deontic modality in Tae' language. Epistemic and deontic modality in Tae' describe as declarative, subjunctive, dubitative, imperative, desiderative and volition, interrogative, and possibility form.
\end{abstract}

Key words: modality, epistemic, deontic, Tae's language, grammatical-lexical view

\section{Introduction}

Modality can be defined as a philosophical concept, as a subject of the study of logic, or as a grammatical category. There are many definitions and classifications of modal phenomena. Even if we compiled an exhaustive and precise set of existing definitions, we would still be providing a limited view on what modality is. From a philosophical standpoint, von Fintel (2006: 1) defines modality as "a category of linguistic meaning having to do with the expression of possibility and necessity." In this sense "a modalized sentence locates an underlying or prejacent proposition in the space of possibilities." Von Fintel describes several types of modal meaning (alethic, epistemic, deontic, bouletic, circumstantial, and teleological), some of which are introduced by von Wright (1951), and shows that modal meaning can be expressed by means of several types of expressions, such as modal auxiliaries, semimodal verbs, adverbs, nouns, adjectives, and conditionals

Palmer defines two types of modality: epistemic, used by speakers "to express their judgement about the factual status of the proposition," and evidential, used "to indicate the evidence that they have for its factual status" (Palmer, 1986: 89). He also defines two types of event modality: deontic, which relates to obligation or permission and to conditional factors "that are external to the relevant individual," and dynamic, where the factors are internal to the individual (Palmer, 1986: 9-13). Additionally, Palmer indicates other categories that may be marked as irrealis and may be found in the mood system: future, negative, interrogative, imperative-jussive, presupposed, conditional, purposive, resultative, wishes, and fears. Explain how modality relates to tense and aspect: The three categories are concerned with the event reported by the utterance, whereas tense is concerned with the time of the event and aspect is "concerned with the nature of the event in terms of its internal temporal constituency" (Palmer, 1986: 13-16).

XLinguae, Volume 10, Issue 4, October 2017, ISSN 1337-8384, eISSN 2453-711X 
Körtevély (2009: 403-430 in Hansen and De Haan 2009) discussed modals in Hungarian. In his paper, he found that there were numerous ways to express modality in this language. The ways concern possibility, necessity, and volition. Those can be expressed by modal verbs or auxiliaries, modal adjectives, modal particles, modal tags, and also by a modal affix. Furthermore, Mettouchi (2009: 431456 in Hansen and De Haan 2009) wrote about mood and modality in Berber. In her study, she found that the modal system in Berber is linked to the fundamental nontemporal and deictic feature of language. It depends on the position of the speakers, with respect to whom situations manifest themselves as real or non-real. She also focused on elaborations of basic particles and TMA marked stems in structure of this language.

Knowing how modality is expressed across languages is relevant for the computational linguistics community. Concepts related to modality that have been studied in computational linguistics are: hedging, evidentiality, uncertainty, factuality, and subjectivity. The same thing stated by Roses and Caroline (2012:224) that modality is a grammatical category that allows the expression of aspects related to the attitude of the speaker towards her statements in terms of degree of certainty, reliability, subjectivity, sources of information, and perspective.

Further, Palmer (1986: 7, 21) states that the distinction between the notions of mood and modality is similar to that between tense and time, or between gender and sex. In short, 'modality' deals with conceptual categories, whereas 'mood' refers to a set of formally marked linguistic distinctions. In many languages in the world mood can be found by identifying grammatical categories. Traditionally it can be expressed by verbal morphology, but modality is not expressed in all languages in this way; it may also be expressed by modal verbs and particles which may be quite separated from the verb. According to Asher (1994: 2536 in Palmer 1986), modality concerns attitudes and opinions of the speaker, speech acts, subjectivity, non-factivity, nonassertion, possibility and necessity, with special reference to the English modal verbs, a group of the concepts that include the possibility, necessity, obligation, volition, and ability.

This is the same view that was expressed by Lyons (1977: 452), who said that the notion of modality is something that is related with the opinion and attitude of the speaker. He made a further distinction into two kinds of modality, namely, epistemic modality and deontic modality, and stipulated that epistemic modality is concerned with matters of knowledge, belief (1997: 793) or opinion rather than fact (1997: 681-2), while, deontic modality is concerned with the necessity or possibility of acts performed by morally responsible agents (1997: 823).

After this, Bybee and Fleischman (1995) in Nordström (2010: 15) argued that modality is divided into three different domains: speech-act (speaker-oriented) moda. 


\begin{tabular}{|llc|}
\hline Speech-act modality & Propositional modality & Event modality \\
\hline - imperative & - epistemic modality & - deontic modality \\
- hortative & - evidential modality & - dynamic modality \\
- jussive & - indicative-subjunctive & \\
- prohibitive & - realis-irrealis \\
- optative & - conditional \\
- interrogative & \\
\hline & \\
\hline & General Subordinators \\
\hline
\end{tabular}

Figure 2: Geographical region coverage in selected English language textbooks

Those types of modality can be marked by general subordinators. Additionally, modality can be expressed in a number of other ways; common strategies are the use of special modal verb forms, or the use of modal verbs or particles (Nordström, 2010: 16). Nordström further proposes that modal verb forms ('moods') can be subdivided into a number of subcategories, i.e., declarative, indicative, subjunctive, realis, irrealis, conditional, interrogative, imperative, optative, hortative, jussive, and prohibitive, whereas the modal markers can be subcategorized as epistemic, evidential, deontic, and dynamic.

A similar conception of mood is adhered to in Bybee (1985: 165) and Palmer (1986:21-22). Bybee considers mood to be a marker on the verb that signals how the speakers choose to put the proposition into the discourse context. She further describes mood as grouping of indicative, imperative, and subjunctive. Indicative means the sign of declarative sentences, imperatives means the form of the verb used in issuing direct commands or orders, and subjunctive means the term usually applied to special finite verb forms associated with certain types of subordinate constructions (1985: 170-186).

Palmer (1986: 21-22) distinguishes three characteristics of the category of mood. These are; (1) mood is traditionally restricted to a category expressed in verbal morphology, (2) mood functions as a subjunctive or as a subordinate sentence, and (3) mood is generally restricted to indicate subjunctive, imperative, and optative. These characteristics, however, are not applicable in all languages in the world. Palmer admits that modal features of this type are expressed only in some languages, for instance, in French, German, Latin, and Greek.

A recent study about TMA is presented by Hansen and De Haan (2009). Their main concern is with modals in the languages in Europe, which are described from a genetic perspective, with special reference to the five Germanic languages English, Dutch, German, Danish, and Icelandic (see also Mortelmans, Boye, and van de Auwera 2009:11-69 in Hansen and De Haan, 2009). In their analysis, they use Lehmann's parameters of grammaticalization. These parameters concern three aspects of grammaticalisation, namely, weight, cohesion, and variability. A similar study is conducted by Tsangalidis (2009: 139-163 in Hansen and De Haan 2009). He discusses modals in Greek, and again this author focuses on the presentation of the modal categories in this language using Lehmann's parameters of grammaticalisation. He argues that there are three modal categories in Greek, namely (1) a morphological mood distinction, (2) periphrastic combinations with three modals particles, and (3) a set of two special verbs of necessity and possibility. 
Based on the above arguments, the research aims to discuss modality in Tae' language expressed in grammatical and lexical feature. Thus, the problem in this research is how are the forms of modality in Tae' language.

\section{Methodology}

This research uses the descriptive method which is aimed at finding detailed and complete data. The collecting data was done by way of library study. It means that the writer has collected the data by reading some books, journals, and other sources that are related with this research, particularly theories and researches about modality. The method used to analyze the data was the theory of Palmer F. R., (1986), Van Minde (1997), Bybee (1985), and Nordström, (2010) as discussed above.

\section{Results and Discussion}

From a more semantic point of view, Quirk (1985: 219-239) differentiates the modality in intrinsic and extrinsic modality. Intrinsic modalities cover permission, obligation, and volition, whereas, the extrinsic modalities cover possibility, necessity, and prediction. The above distinctions, specifically, seem to be visible in Tae' language. The following sentence describes one of them. It is named of;

\section{Declarative}

(1) meloki te' beppa ato tae?

melo -ki te' beppa ato tae?

MOD 2ABS DEM cake or not?

'Do you want this cake or not?

Obviously, the lexical verb at the above sentence is marked by word melo 'want' encodes an interrogative sentence that has meaning as desiderative or volition modality. In Quirk's terms this is called a case intrinsic modality (Quirk 1985). Furthermore, Tae' also uses the prefix la- to emphasize desire, as in the following sentence;

(2) laurang

la- urang

MOD rain

'It's going to rain'

Grammatical feature which is described by the prefix la indicates volition modality and it functions as grammatical feature. In some cases, however, the prefix la- has a different meaning in sentences. It depends on the context of sentences itself.

Palmer's (1986: 26-27) point of view states that modality can be expressed by speaker's opinion or makes a statement that he believes to be true. This is called as declarative modality. The following sentences illustrate this:

$$
\begin{aligned}
& \text { parallu kubengko pangaja nasaba lamusalai te' tondokta. } \\
& \text { parallu ku- beng - } k \text { po pangaja nasaba } \\
& \text { salai te' tondok -ta }
\end{aligned}
$$


that DEM 3ERG MOD PASS say LOC DEM N PASS place

3ERG easy CAUS look that 3ERG say indeed last that

go LOC here house POSS Labaco

'If we want to go out, we need to tell people at home, so they know if we go to out (Labaco's home)'

\section{tae'na parallu disengkei to' padantarupa tau}

tae' na- parallu di- sengke $-i$ to' padanta rupa tau

NEG 3ERG-PL MOD PASS angry 2ABS DEM fellow face human

'We needn't to be angry with human beings'

(We do not need to be angry with human beings)

In general, all sentences above express declarative mood (Nordström 2010, Palmer 1986, Bybee 1985). The presence of the modal auxiliary parallu expresses the epistemic modality, particularly in necessity (Nordström 2010, Quirk 1985). Specifically, sentence (3) and (4) indicate subjunctive mood which is expressed by the subordinate clauses saba 'because' and kumua 'that' (Nordström 2010, Giorgi \& Pianesi 1977), while sentence (5) expresses negation of modality (Giorgi \& Pianesi 1977). The simple negative tae' that follows the modal verb parallu, and affirms that the activity to scold people is not important or forbidden (Nordström 2010).

particles:

Furthermore, another declarative encoding option is effectuated by

(6) narundu' bang sau to' salu

na- rundu bang sau to' salu

3ERG-PL follow MOD LOC DEM river

'They just follow to that river'

(7) mallai omi undi rundui

mallai omi undi rundu $-i$

run MOD behind follow 3ABS

'They run again to follow him'

The particle bang in sentence 6 means 'just', and indicates declarative mood, as does the modal adverb omi 'again' in sentence 7. These constructions are denoted as epistemic modality (Nordström 2010). The similarity mood systems in Tae' can be seen in the following sentence;

$$
\begin{aligned}
& \text { natitok bangmi to' peporinna } \\
& \text { na- titok bang -mi to' pe- pori -na } \\
& \text { 3ERG-SG peck MOD PFV DEM ACT-N bundle 3POSS } \\
& \text { 'The chicken had only picked his bundle' }
\end{aligned}
$$

Again, the particle bang 'just/only', followed by the suffix -mi, indicates declarative mood (Palmer 1986, Bybee \& Fleischman, 1995). The whole of this construction emphasizes that the process of pecking had already occurred in the past. In other words, the speaker expresses as his opinion that what he says is true. This sentence also indicates the perfective aspect. However, I do not discuss such cases here.

Another construction of mood features the particle sia.

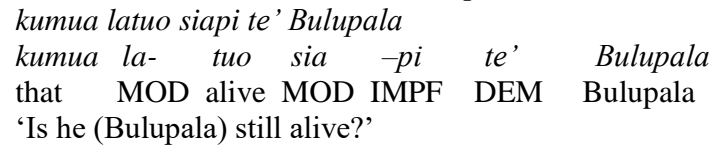


In this sentence, the mood marker la-, followed by the finite verb tuo 'alive', indicates subjunctive mood, which is marked by the conjunction kumua 'that' (Palmer 1986). Moreover, the suffix -pi and the modal adverb sia emphasizes the doubt of the speaker towards the presence of Bulupala. The speaker expects that Bulupala has died but it may just be possible that he is still alive. This construction is also called dubitative mood (Palmer 2001: 25). Dubitative is used when the speaker has doubts about the veracity of the proposition.

As we can see, the particles bang and sia are not independent particles, as they are sometimes followed by suffixes -mi, -mo-, - $p i$, and -pa. The particle omi, on the other hand, is an independent particle.

\section{Imperative}

The imperative mood in Tae' is illustrated by the following sentence:

$$
\begin{aligned}
& \text { rebu'i kade kawalimmu } \\
& \text { rebu' }-i \quad \text { kade kawali } \\
& \text { unplug } 3 \mathrm{ABS} \text { MOD dagger } \\
& \text { 'Pull your dagger, please!' }
\end{aligned}
$$

The word kade indicates imperative mood (Palmer 1986, Bybee 1985, Nordstrom 2010). The speaker asks the agent to do a thing, namely, to pull the dragger from his body. Thus, the speaker expresses a request to the hearer. Other options to express requests in Tae' are illustrated by the following sentences:

(11) summoko mai

$$
\begin{aligned}
& \text { sum -mo -ko mai } \\
& \text { out PVF 2ABS let } \\
& \text { 'You get out please!' } \\
& \text { maiko jolo inde 'Abo" anakku } \\
& \text { mai -ko jolo inde 'Abo' anak -ku } \\
& \text { come 2ABS first here 'Abo' child POSS } \\
& \text { 'Come here firstly my son 'Abo'. }
\end{aligned}
$$

The two sentences above indicate imperative mood. Sentence (11), particularly, expresses the situation where the speaker requests the addressee to come out from the place (cave). Sentence (12) expresses that the speaker wants his child to come to him to hear some advices before his child goes to a foreign country.

Yet another form of imperative mood in Tae' is illustrated by the following sentences;

$$
\begin{aligned}
& \text { dialari ia baju } \\
& \text { di- ala -ri ia baju } \\
& \text { PASS take MOD PRO dress } \\
& \text { "Take a dress!' } \\
& \text { manjori ia lako } \\
& \text { manjo-ri ia lako } \\
& \text { go MOD PRO there } \\
& \text { 'Go there!' }
\end{aligned}
$$

awogading tuo tunggare langngam bone

awogading tuo tungga -re langngam bone

bamboo grow alone MOD cliff humus

'Grow alone on the humus cliff!' 
Sentences (13), (14), and (15) indicate imperative mood by the use of the suffixes $-r i$ and $-r e$. These suffixes function as particles. Interestingly, the word le, meaning 'please', in sentence (16), also functions as a particle which expresses an imperative mood, in particular as a sentence request or a sentence order.

In addition, Tae' also has negations that indicate prohibitive-imperative or negative-imperative mood (Palmer 1986). This will be illustrated by the following sentences;

$$
\begin{aligned}
& \text { dau manjo, suleko mai } \\
& \text { dau manjo, sule -ko mai } \\
& \text { NEG go, back 2ABS here } \\
& \text { 'Do not go, come back here' }
\end{aligned}
$$

$$
\begin{aligned}
& \text { dau kumarrak } \\
& \text { dau kumarrak } \\
& \text { NEG cry } \\
& \text { 'Do not cry' }
\end{aligned}
$$

In these sentences, the prohibitive is indicated by the negation particle dau 'not', and the verb is in its stem form. A different form of prohibitive is illustrated in the following sentences:

$$
\begin{aligned}
& \text { dau mumanjo lako to' gau kadake } \\
& \text { dau mu- manjo lako to' gau kadake } \\
& \text { NEG 2ERG go to DEM act wrong } \\
& \text { 'You don't have to go to the wrong act' } \\
& \text { daumu sibobo } \\
& \text { dau mu- si- bobo } \\
& \text { NEG 2ERG RECIP fight } \\
& \text { 'You don't have to fight each other' }
\end{aligned}
$$

Here, the simple negative $d a u$ 'don't' is followed by the prefix $m u$ - on the verb. The whole construction indicates that, in the opinion of the speaker, a certain situation need not be the case, and can therefore be regarded as a warning or a prohibition.

\section{Desiderative and Volition}

Consider the following sentence:

$$
\begin{aligned}
& \text { langinu' } i \text { wai jiong salu } \\
& \text { la- nginu' }-i \text { wai jiong salu } \\
& \text { MOD drink 3ABS water LOC river } \\
& \text { 'She wants to drink the water in the river'. }
\end{aligned}
$$

Grammatically, this sentence describes desiderative mood by way of the prefix $l a$-. The prefix $l a$ - 'want', followed by the verb inu 'drink' and the suffix $-i$ as absolutive marker, expresses desire or wish. Semantically, this construction can be 
rated as a case of volitional modality (Quirk 1985). Finally, the auxiliary verb melo can be constructed in a negative sentence, such as the following:

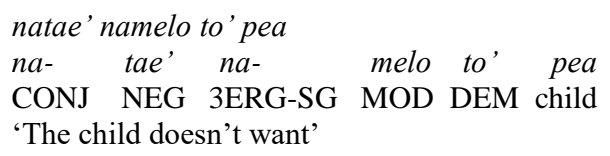

In this construction, the negation element is tae' 'no', which has the conjunction $n a$ as its prefix. The use of natae' emphasizes the rejection of the actor (Bybee 1995, Nordstrom 2010, Giorgi \& Pianesi 1977). The negation tae 'no' can be regarded as metalinguistic negation (Palmer 1986).

The encoding of conditional modality in Tae' is illustrated by the following sentence;

$$
\begin{aligned}
& \text { iake lamanjoko lako tondokna tau } \\
& \text { iake la- manjo -ko lako tondok }-n a \\
& \text { if MOD go } 2 \mathrm{ABS} \text { to country } 3 \text { POSS people } \\
& \text { 'If you want to go to the people's country' }
\end{aligned}
$$

As we can see, a conditional clause in Tae' is introduced by the subordinating conjunction iake 'if'. Initial conjunctions are a feature of all sorts of subordinated clauses, as can be seen from the following example:

$$
\begin{aligned}
& \text { iake lamannasukan kipajiori to' karangan } \\
& \text { iake la- ma- nasu -kan ki- pa- jio } \\
& \text {-ri to' karangan } \\
& \text { If MOD INTR cook 1ABS-PL 1ABS- PL CAUS in } \\
& \text { MOD DEM sand } \\
& \text { 'If we want to cook, we just put in the sand' }
\end{aligned}
$$

\section{Interrogative}

Palmer (1986: 30) states that the interrogative is commonly marked by introductory particles or pronouns. Tae' is a language in which interrogative sentences show these features. In the following examples, the question is introduced by the interrogative adverb mangapa 'why' and the interrogative phrase apa sanganna 'what's up':

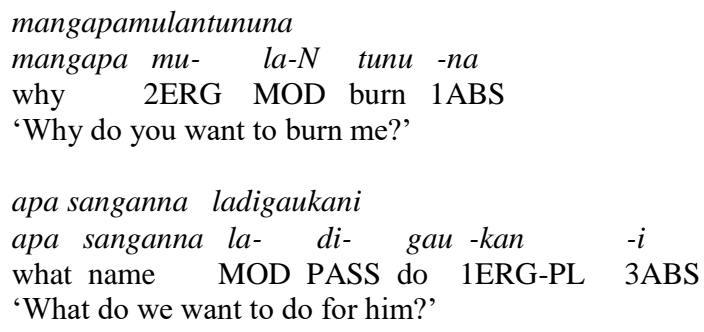

As we saw in the previous section, the verbal prefix la- in these sentences indicates desiderative mood that established by grammatical feature.

Yes/no-questions in Tae' typically contain (combinations of) interrogative particles, such as sia and raka. An example is: Hereafter, the following sentence describes other particles in Tae' that indicate mood system; 


$$
\begin{aligned}
& \text { mubela siaraka } \\
& \text { mu- bela sia raka } \\
& \text { 2ERG can MOD MOD } \\
& \text { 'Could you?' }
\end{aligned}
$$

Clearly that, the interrogative particles sia and raka at the above sentence are formed from lexical feature.

\section{Possibility}

Possibility in Tae' is encoded by modal verbs, as in the following sentence:

$$
\begin{aligned}
& \text { ah marawa ia to', } \text { kubela } \\
& \text { ah marawa ia to' } \mathrm{ku}^{-} \text {bela } \\
& \text { INTRJ easy PRO DEM } 1 \mathrm{ERG} \text { can } \\
& \text { 'Ah, it's easy, I can'. }
\end{aligned}
$$

The auxiliary bela 'can' indicates ability. Another modal auxiliary, wa'ding, has a somewhat dubitative force: it expresses the speaker lacks of confidence in the proportion expressed (Palmer 1986: 59) and might be translated as 'may' or 'can'. Thus, in a sentence like 28 , it should be understood that the event of becoming a survivor is still not true:

$$
\begin{aligned}
& \text { wa'dingko salama } \\
& \text { wa'ding }- \text {-ko salama } \\
& \text { MOD 2ABS survivor } \\
& \text { 'You may be a survivor' }
\end{aligned}
$$

Wa'ding also indicates prediction (Quirk 1986) or possibility (Palmer 1986). It denotes the possibility of a given proposition's being or becoming true (Quirk 1986: 223).

$$
\begin{aligned}
& \text { wa'dingi narundu bijammu } \\
& \text { wa'ding }-i \quad n a-\text { rundu bija -mu } \\
& \text { MOD 3ABS 3ERG follow son 2POSS } \\
& \text { 'It may be followed by your son' } \\
& \text { (31) wa'ding kimasolang } \\
& \text { wa'ding }-k i \quad \text { masolang } \\
& \text { MOD 3ABS-PL hurt } \\
& \text { 'We may hurt' } \\
& \text { 'We may hurt' }
\end{aligned}
$$

Furthermore, the auxiliary verb wa'ding can be used to express epistemic possibility. In this case, it can be rendered as 'can', indicating a necessity, or - when co-occurring with the negation marker tae' - a prohibition.

$$
\begin{aligned}
& \text { iato' atoran agama tae'nawa'ding dipaningo-ningoi } \\
& \text { ia- to' atoran agama tae' na- wa'ding di- } \\
& \text { ningo-ningo - } i \text { pa- } \\
& \text { PRO DEM rule religion NEG 3ERG MOD PASS ACTN-N } \\
& \text { play-play 3ABS } \\
& \text { 'The rules of religion cannot be played' }
\end{aligned}
$$


anu taepa nawa'ding

anu tae -pa na- wa'ding

it NEG IMPF 3ERG MOD

'It cannot be allowed yet'

Another form of negation, which functions as an indicator as deontic modality is illustrated in the following sentence;

$$
\begin{aligned}
& \text { tae' najaji, mustimanjoko } \\
& \text { tae' na- jaji, musti manjo } \\
& \text { NEG 3ERG so, MOD go } \\
& \text { 'Unsuccessful, you must go' }
\end{aligned}
$$

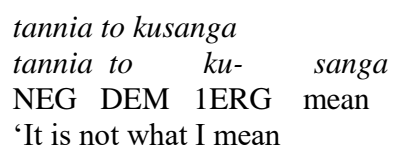

The use of the auxiliary verb musti 'must' indicates deontic modality (Nordström 2010, Warnsby 2006, Bybee 1985, Palmer 1986). It is mandatory/obligatory/compulsory that you must go because the event of going will definitely happen (Quirk 1985). In other words, the speaker is confident that the addressee will go. In further, negation tae' and tannia at above sentences indicate as negative statements.

\section{Conclusion}

Summing up the results discussion of modality marking in Tae', it can be concluded that modality marking in Tae' can be expressed by grammatical and lexical feature. Grammatical modality of Tae' established through affixation process, i.e. prefix la-, and suffixes -ri, -ra functioning as verbs and particles. Further, modality in Tae' is also established by lexical feature using the words melo, parallu, musti, bela, wa'ding, bang, omi, sia, kade, le', dau, tae, tannia, saba, iake, and kumua functioning as auxiliary verbs, particles, negations, and conjunctions. Semantically, these forms mark epistemic and deontic modality in Tae' language. Epistemic and deontic modality in Tae' describe as declarative, subjunctive, dubitative, imperative, desiderative and volition, interrogative, and possibility form.

\section{Bibliographic References}

BYBEE, J. - FLEISCHMAN, Z. 1995. Modality and Grammar in Discourse (Typological Studies in Language 32). Amsterdam and Philadelphia: John Benjamins. ISBN 978-9027229250.

BYBEE, J. L. 1985. Morphology. A study of the Relation between Meaning and Form. Amsterdam: John Benjamins. ISBN 978-9027283917.

GIORGI, A. - PIANESI, F. 1997. Tense and aspect (from semantics to morphology). $1^{\text {st }}$ edition. New York: Oxford University Press. ISBN 987-0195091039.

HANSEN, B. - DE HAAN, F. 2009. Modals in the Languages of Europe. A Reference Work. New York: Mouton de Gruyter. ISBN 978-3-11-021920-3.

KAI VON FINTEL. 2006. Modality and Language. In D. M. Borchert, editor, Encyclopedia of Philosophy. MacMillan Reference, Detroit, MI, second edition. Available online: http://mit.edu/fintel/fintel-2006-modality.pdf. p. 1-16 ISBN 9780286957806.

LYONS, J. 1997. Semantics. Vol. 2. Melbourne: Cambridge University Press. ISBN 978-0521291866. 
MINDE, D. VAN. 1997. Malayu Ambong. Phonology, Morphology, Syntax. Leiden: The Netherlands. ISBN 90-73782-94-5.

NORDSTROM, J. 2010. Modality and Subordinators. Amsterdam: John Benjamins. ISBN 978-9027205834.

PALMER, F. R. 1986. Mood and Modality. $1^{\text {st }}$ edition. London: Cambridge University Press. ISBN 978-0521800358.

PALMER, F. R. 2001. Mood and Modality. $2^{\text {nd }}$ edition. London: Cambridge University Press. ISBN 978-0521804790.

QUIRK, R. ET AL. 1985. A Comprehensive Grammar of the English language. London: Longman. ISBN 978-0582517349.

MORANTE, R. - SPORLEDER, C. 2012. Modality and Negation: An Introduction to the Special Issue. Association for Computational Linguistics, Volume 38, Number 2. pp. 223-260. ISSN 0891-2017.

VON WRIGHT - GEORG, H. 1951. An Essay in Modal Logic. North Holland, Amsterdam. ASIN B00181MC11.

WARNSBY, A. 2006. (De) coding Modality. The case of Must, May, Maste, and Kan. Sweden: Lund University. ISBN 91-975158-2-5.

Words: 4160

Characters: 28121 (15,7 standard page)

assoc. prof. Kisman Salija

Dr. Idawati Garim

Faculty of Languages and Literature

Universitas Negeri Makassar

Jalan Dg. Tata, Makassar

South Sulawesi,

Indonesia

kismansalija@unm.ac.id

garimidawati@gmail.com

Dr. Jusmianti Garing

Balai Bahasa Sulawesi Selatan

Jalan Sultan Alauddin Km. 7 Tala Salapang

South Sulawesi,

Indonesia

garingjusmianty@yahoo.co.id 